University of Nebraska - Lincoln

DigitalCommons@University of Nebraska - Lincoln

Biochemistry -- Faculty Publications

Biochemistry, Department of

October 2006

\title{
An ascorbate-reducible cytochrome b561 is localized in macrophage lysosomes
}

\author{
De-liang Zhang \\ University of Nebraska - Lincoln \\ Dan Su \\ University of Nebraska - Lincoln \\ Alajos Berczi \\ Hungarian Academy of Sciences, Szeged, H-6701, Hungary \\ Amy Vargas \\ Hungarian Academy of Sciences, Szeged, H-6701, Hungary \\ Han H. Asard \\ University of Nebraska - Lincoln, hasard2@unl.edu
}

Follow this and additional works at: https://digitalcommons.unl.edu/biochemfacpub

Part of the Biochemistry, Biophysics, and Structural Biology Commons

Zhang, De-liang; Su, Dan; Berczi , Alajos ; Vargas , Amy ; and Asard, Han H., "An ascorbate-reducible cytochrome b561 is localized in macrophage lysosomes" (2006). Biochemistry -- Faculty Publications. 11. https://digitalcommons.unl.edu/biochemfacpub/11

This Article is brought to you for free and open access by the Biochemistry, Department of at DigitalCommons@University of Nebraska - Lincoln. It has been accepted for inclusion in Biochemistry -- Faculty Publications by an authorized administrator of DigitalCommons@University of Nebraska - Lincoln. 


\title{
An ascorbate-reducible cytochrome b561 is localized in macrophage lysosomes
}

\author{
De-liang Zhang ${ }^{\mathrm{a}, \mathrm{c}}$, Dan $\mathrm{Su}^{\mathrm{a}}$, Alajos Bérczi ${ }^{\mathrm{b}}$, Amy Vargas ${ }^{\mathrm{a}}$, Han Asard ${ }^{\mathrm{a}, \mathrm{d}, *}$ \\ a Department of Biochemistry, University of Nebraska-Lincoln, Lincoln, NE 68588, USA \\ ${ }^{\mathrm{b}}$ Institute of Biophysics, Biological Research Center, Hungarian Academy of Sciences, Szeged, H-6701, Hungary \\ ${ }^{c}$ Cell Biology and Metabolism Branch, National Institute of Child Health and Human Development, NICHD, Bethesda, MD 20892, USA \\ ${ }^{\mathrm{d}}$ Department of Biology, University of Antwerp, Groenenborgerlaan 171, B-2020, Antwerp, Belgium
}

Received 15 April 2006; received in revised form 18 July 2006; accepted 24 July 2006

Available online 22 August 2006

\begin{abstract}
Cytochromes b561 (Cyts b561) are a family of intrinsic membrane proteins involved in ascorbate-mediated transmembrane electron transport. The chromaffin granule Cyt b561 (CGCytb) is believed to transport electrons donated by extravesicular ascorbate (ASC) across the membrane to intravesicular monodehydroascorbate (MDA) supporting catecholamine synthesis in neuroendocrine tissues. Another isoform, the duodenal Cyt b561 (Dcytb), was reported to have ferric reductase activity, possibly facilitating intestinal iron uptake. Herein, a new Cyt b561 homologue, LCytb (for lysosomal Cytb561) was found expressed in the late endosomal-lysosomal membrane. LCytb shared high sequence similarity with CGCytb (45\% identity) and Dcytb (42\% identity). Moreover, four heme-coordinating His residues, and putative ASC and MDA binding sites were highly conserved. Recombinant LCytb exhibited an ASC-reducible b-type Cyt absorbance spectrum with $\alpha$-band maximum at $561 \mathrm{~nm}$ in the spectrum of the reduced protein. Northern blots and Western blots revealed that LCytb was predominantly expressed in lung, spleen, thymus, testis and placenta. In situ hybridization and immunofluorescence studies further demonstrated that the protein was expressed in the alveolar macrophages of the lung, in the white pulp of the spleen, widespread in the thymus, and in the Sertoli cells of the testis. Sequence analysis indicated the presence of a (DE)XXXL(LI)-type signal in the C-terminal of the protein, predicting a late endosomal-lysosomal subcellular localization. This localization was confirmed by double labeling experiments in RAW264.7 and 293 cells, stably transfected with LCytb.
\end{abstract}

(C) 2006 Elsevier B.V. All rights reserved.

Keywords: Lysosomal cytochrome b561 (LCytb); Chromaffin granule cytochrome b561 (CGCytb); Duodenal cytochrome b561 (Dcytb); Macrophage, Lysosome

\section{Introduction}

Chromaffin granule Cyt b561 (CGCytb) is an intrinsic membrane protein expressed in neuroendocrine tissues. CGCytb is believed to function as an electron carrier transporting electrons from extravesicular ASC to intravesicular MDA to recycle ASC, supporting catecholamine synthesis [1]. It has only recently become evident that CGCytb is a member of a newly described protein family, ubiquitously present in almost all living kingdoms [2]. Using the CGCytb protein sequence, genome analysis has revealed the presence of multiple Cyt b561

\footnotetext{
* Corresponding author. Department of Biology, University of Antwerp, Groenenborgerlaan 171, B-2020, Antwerp, Belgium. Tel.: +32 3265 3638; fax: +3232653417.

E-mail address: han.asard@ua.ac.be (H. Asard).
}

isoforms in many species, with, for example, five isoforms in mice and four in Arabidopsis thaliana [2,3]. Although very little is known about any of the other Cyt b561 isoforms, sequence conservation suggests that they all have the structure motifs of Cyts b561, i.e. six putative transmembrane domains, four His residues which coordinate two heme molecules responsible for electron transport, and two putative binding sites involved in binding of ASC and MDA [2,4-6]. The sequence conservation suggests that all members of the Cyt b561 protein family are likely involved in ASC-mediated transmembrane electron transport. However, the localization and importance of the Cyt b561 isoforms other than CGCytb remain to be determined.

The so-called duodenal Cyt b isoform (Dcytb, or Dcybrd1) was localized in the mouse duodenal apical brush-border membrane [6]. Dcytb shared between $45 \%$ and $50 \%$ similarity to other members of the Cyt b561 family [6]. Subtractive cloning 
and expression of the Dcytb gene in Xenopus oocytes revealed that the gene encoded a protein with ferric reductase activity [6]. Dcytb-mediated reduction of ferric iron to ferrous iron is likely to facilitate iron absorption in the duodenum by DCT1 (Divalent cation transporter 1)/Nramp2 (Natural resistance-associated macrophage protein 2) [7,8]. However, Gunshin et al. recently reported that knockout of Dcytb had little or no impact on body iron stores, even in animals with low iron diet. This indicates that the role of Dcytb is far from clear $[9,10]$.

Another Cyt b561 homologue, encoded by the gene 101F6, is localized in a $120-\mathrm{kb}$ critical tumor deletion region (found in lung and breast cancers) of human chromosome 3 p21.3 [11]. Forcedexpression of wild-type 101F6 in human lung cancer cell lines significantly inhibited tumor cell growth by induction of apoptosis and alteration of cell cycle processes [12]. Moreover, intratumoral injection of Ad-101F6 significantly suppressed the growth of tumor xenograft and inhibited experimental lung metastases in nu/ nu mice, but the underlying mechanism remains unknown [12].

As the Cyts b561 constitute a poorly characterized family of membrane proteins, herein we investigated the properties and the cellular and subcellular localization of another member of this protein family identified by genome analysis. Our results demonstrate that this Cyt b561 was localized predominantly in the late endosomal-lysosomal membranes and the protein has therefore been named LCytb.

\section{Materials and methods}

\subsection{Plasmid constructs and yeast transformation}

Standard PCR methods were used to amplify the gene (accession number: NM_201351) encoding a putative new Cyt b561 from total mouse kidney RNA. Primers were designed to include EcoRI and SpeI restriction sites for cloning into the pESC-His expression vector (Stratagene, La Jolla, CA), downstream of the GAL10 Gal-inducible promoter. For transformation, yeast cells (strain YPH499, ura3-52 lys2-801amberade2-101ochre trp1- $\Delta 63$ his3- $\Delta 200$ leu2- $\Delta 1$ ) were grown in YPAD medium (Stratagene, La Jolla, CA) and transformation was performed according to the manufacturer's instructions. Transformed cell lines were selected on SD dropout medium lacking His (SD-His). For the induction of protein expression, overnight cultures were grown in SD-His and were transferred to $450 \mathrm{ml}$ of synthetic Gal minimal medium containing $2 \%\left(\mathrm{w} \mathrm{v}^{-1}\right)$ Gal and supplemented with $1 \mathrm{mM}$ ASC.

\subsection{Plasmid constructs, cell culture and transfection}

The mouse macrophage-derived cell line, RAW264.7 (ATCC) was cultured in DMEM medium containing 100 units $\mathrm{L}^{-1}$ penicillin, 100 units $\mathrm{L}^{-1}$ streptomycin, $10 \% \mathrm{FBS}$ at $37{ }^{\circ} \mathrm{C}$ under $5 \% \mathrm{CO}_{2} .293$ cells derived from primary human embryonic kidney (GIBCO, Invitrogen Corporation) were cultured in the same condition as the RAW264.7 cells, except that they were supplemented with $0.1 \mathrm{mM}$ non-essential amino acids. The LCytb gene was cloned into pcDNA3.1-vector (Invitrogen Life Technologies) with $X b a \mathrm{I}$ and EcoRI restriction sites, and transfected into the RAW264.7 and 293 cells using the FuGENE-6 transfection reagent (Roche Applied Science). The stably transfected cell clones were screened with G418 $1 \mathrm{mg} \mathrm{ml}^{-1}$ for RAW264.7 and $400 \mu \mathrm{g} \mathrm{ml}^{-1}$ for 293 cells for 2 weeks.

\subsection{Yeast microsomal membrane preparation and stripping}

Yeast cells transformed with the LCytb gene or empty pESC-His vector were cultured overnight or longer until the $\mathrm{OD}_{600}$ reached $0.6-0.8$. The yeast microsomal membrane fraction was prepared as reported previously [13]. To remove loosely bound proteins and proteins trapped inside sealed membrane vesicles, membranes were 'stripped' as follows: membrane fractions were suspended in $10 \mathrm{ml}$ storage buffer, after addition of $0.05 \mathrm{ml}_{5} \%\left(\mathrm{w} \mathrm{v}^{-1}\right)$ Triton $\mathrm{X}$ 100 and $5 \mathrm{mM}$ ASC, mixed vigorously and incubated on a rocker for $15 \mathrm{~min}$ at room temperature. Then $10 \mathrm{ml}$ of $2 \mathrm{M} \mathrm{KCl}$ was added, and the fraction was incubated on the rocker for another $15 \mathrm{~min}$. After addition of $20 \mathrm{ml}$ nanopure $\mathrm{H}_{2} \mathrm{O}$ the fraction was again incubated for $15 \mathrm{~min}$ on the rocker. Membranes were collected by centrifugation at $75,000 \times g$ for $75 \mathrm{~min}$ at $4{ }^{\circ} \mathrm{C}$, resuspended in storage buffer ( $25 \mathrm{mM}$ MES-Tris, $\mathrm{pH} 6.8$, containing $1 \%$ ( $\mathrm{w} \mathrm{v}^{-1}$ ) glycerol), and stored at $-85{ }^{\circ} \mathrm{C}$ until use. Protein concentration was determined using a modified Lowry method with BSA as the standard [14]

\subsection{Animal organ microsomal membrane and cell lysate preparation}

Animal organs (Pel-Freez biologicals, Rogers, AR) were homogenized in 10 volumes of ice-cold homogenization buffer (50 mM Tris- $\mathrm{HCl}$ pH 7.0, $150 \mathrm{mM}$ $\mathrm{NaCl}, 1 \mathrm{mM}$ ASC, $2 \mathrm{mM}$ EDTA, $1 \mathrm{mM}$ PMSF, $1 \mu \mathrm{g} \mathrm{ml}^{-1}$ each of leupeptin, aprotinin, pepstain A, antipain, and chymostatin). Debris and unbroken cells were removed by centrifugation at $5000 \times \mathrm{g}$ for $10 \mathrm{~min}$, the supernatant was centrifuged at $75,000 \times \mathrm{g}$ for $75 \mathrm{~min}$ at $4{ }^{\circ} \mathrm{C}$ to collect the microsomal membranes, and pellet was resuspended in storage buffer. Stripping of the membranes was performed as described for yeast membranes.

Spleen and lung tissues were homogenized in liquid nitrogen, and kept in Munro's buffer (10 mM HEPES, pH 7.2, $3 \mathrm{mM} \mathrm{MgCl}_{2}, 40 \mathrm{mM} \mathrm{KCl}, 5 \%$ glycerol, $0.2 \%$ NP-40, $5 \mathrm{mM}$ DTT, $1 \mathrm{mM}$ AEBSF, $10 \mathrm{mg} / \mathrm{ml}$ Leupeptin and CompleteTM EDTA free protease inhibitor cocktail (Roche Diagnostics)) for $15 \mathrm{~min}$ on ice. After centrifugation for $10 \mathrm{~min}$ at $13000 \times \mathrm{g}$, the supernatants were kept for Western blot analysis. 293 cells transfected with LCytb or pcDNA3.1-empty vector were cultured until the confluence reached $80 \%$, the cells were collected and rinsed with ice-cold PBS. Then the cell lysate was prepared with lysis buffer $(0.15 \mathrm{M} \mathrm{NaCl}, 5 \mathrm{mM}$ EDTA, $1 \%$ Triton X-100, $100 \mathrm{mM}$ Tris-Cl pH 7.4, 5 mM DTT, $1 \mathrm{mM}$ PMSF, $1 \mu \mathrm{g} \mathrm{ml}^{-1}$ each of leupeptin, aprotinin, pepstain A, antipain, and chymostatin). The sample was centrifuged at $5000 \times g$ for $10 \mathrm{~min}$; the supernatant was stored at $-80{ }^{\circ} \mathrm{C}$ until use. Alveolar macrophages were prepared according to Holt's methods [15], the macrophages lysate was prepared as described for 293 cell.

\subsection{Measurement of Cyt b absorption spectra}

Absorption spectra of membrane-bound Cyt $\mathrm{b}$ in stripped yeast microsomal membrane vesicles were determined from oxidized and reduced spectra recorded in dual wavelength-mode (between 500 and $600 \mathrm{~nm}$ and reference at $601 \mathrm{~nm}$; SLM-Aminco DW2000 spectrophotometer updated by OLIS Inc., Bogart, GA), in $2 \mathrm{ml}$ samples with $1 \mathrm{~nm}$ slit-width, $0.5 \mathrm{~nm} \mathrm{~s}^{-1}$ scan rate, and under continuous stirring. First, Cyts were oxidized by addition of ferricyanide $(0.1 \mathrm{mM}, \mathrm{FeCN})$ and the fully oxidized spectra were recorded. Then, ASC-reduced ( $25 \mathrm{mM} \mathrm{ASC}$ ) and $\mathrm{ASC}+$ dithionite-reduced (after addition of Na-dithionite crystals) spectra were obtained at room temperature. When improvement of the signal to noise ratio was needed, multiple scans were averaged. In calculations, reduced minus oxidized difference spectra and $30 \mathrm{mM}^{-1} \mathrm{~cm}^{-1}$ as molar extinction coefficient at $561 \mathrm{~nm}$ were used. The protein concentration was $2 \mathrm{mg} \mathrm{ml}^{-1}$ throughout the experiments.

\subsection{Northern blot analysis}

A nylon (+) membrane blotted with $20 \mu \mathrm{g}$ of total RNA in each lane from each mouse organ was purchased from Seegene, Seoul, Korea. Northern blots were performed according to the manufacturer's protocol. The template for the LCytb probe consisted of the nucleotides from 570 to 662 bp of the mouse LCytb cDNA, corresponding to the first $93 \mathrm{bp}$ nucleotides of the coding sequence. The single strand DNA probes were synthesized and labeled with ${ }^{32} \mathrm{P}-\mathrm{dCTP}$ by PCR with antisense primer only. The membrane was hybridized with ${ }^{32} \mathrm{P}$-labeled DNA probes at $58{ }^{\circ} \mathrm{C}$ for $16 \mathrm{~h}$, and subjected to autoradiography for $24-72 \mathrm{~h}$.

\subsection{Antibody generation, purification and western blots analysis}

Antibodies were generated in rabbit against a C-terminal peptide ([Cys]KRPDPGALTDRQPLLHDRE) of mouse LCytb. After screening the sera for 
the presence of LCytb-specific antibodies against yeast recombinant LCytb, antibodies were affinity purified using Sulfolink Coupling Gel (Pierce Biotechnology, Rockford, IL) according to the manufacturer's procedure. Membrane proteins were resolved by SDS-PAGE electrophoresis, using 12\% acrylamide gels and transferred onto polyvinylidene difluoride membranes (PVDF, Bio-Rad, Hercules, CA). Each well was loaded with $15 \mu \mathrm{g}$ samples for animal tissues and $1 \mu \mathrm{g}$ sample for yeast recombinant LCytb. Prior to loading, samples were incubated at $37^{\circ} \mathrm{C}$ for $30 \mathrm{~min}$ to denature the sample. Boiling was proved resulting in aggregation of the LCytb and preventing the protein from entering into the gel. LCytb antibodies were used in a 1:200 dilution, and protein-antibody complexes were detected by horseradish peroxidase-conjugated secondary antibodies (ECL detection kit, Amersham-Pharmacia Biotech, Piscataway, NJ). For peptide N-glycosidase F (PNGase F) digestion, aliquots of samples were digested with PNGase F according to manufacturer's instruction (New England Biolabs Inc.), after denaturing for $30 \mathrm{~min}$ at $37{ }^{\circ} \mathrm{C}$ in denaturing buffer.

\subsection{Immunohistochemistry}

Mouse organs removed from anesthetically killed animals were immediately fixed in ice-cold buffered $4 \%$ paraformaldehyde for $48 \mathrm{~h}$ and cryoprotected in $30 \%$ sucrose $/ 0.1$ M PBS for $48 \mathrm{~h}$. The organs were sectioned into $10 \mu \mathrm{m}$ sections, and then air-dried and stored at $4{ }^{\circ} \mathrm{C}$ until use. Sections were boiled in citrate buffer $(0.01 \mathrm{M}, \mathrm{pH} 6.4)$ with a microwave oven for $15 \mathrm{~min}$ for antigen retrieval. Sections were incubated with the primary antibody for $2 \mathrm{~h}$ at RT or overnight at $4{ }^{\circ} \mathrm{C}$, and were incubated with the secondary antibody for $1 \mathrm{~h}$ at RT. The sections were mounted with Gel Mount ${ }^{\mathrm{TM}}$ Aqueous Mounting Medium (Sigma-Aldrich).

For immunocytochemistry, the cells cultured on cover glass were fixed with ice-cold methanol for $5 \mathrm{~min}$. For double-labeling with Lysotracker, the cells were incubated with $100 \mathrm{nM}$ Lysotracker Red DND-99 (Molecular probes, Inc) in DMEM without serum for $30 \mathrm{~min}$ at $37^{\circ} \mathrm{C}$, then rinsed with PBS and fixed in ice-cold buffered $4 \%$ paraformaldehyde for $10 \mathrm{~min}$. The cells were treated with $0.5 \%$ Triton X-100 for 15 min to increase their permeability. The cells were labeled with primary antibodies for $2 \mathrm{~h}$ and secondary antibody for $1 \mathrm{~h}$ at RT. The dilution was 1:50 for rabbit-anti-mouse LCytb, rat-antimouse MAC-3 and rat-anti-mouse Lamp2 (BD Biosciences, San Diego, CA), was 1:60 for CY2 labeled donkey-anti-rabbit and CY5 labeled donkey-anti-rat (Jackson ImmunoResearch Laboratories, West Grove, PA). The samples were observed under a fluorescence microscope (Nikon Eclipse TE300), or a confocal microscope (Olympus FV500).

\subsection{In situ hybridization (ISH)}

Sense and anti-sense cRNA probes were synthesized with the DIG RNA labeling kit (SP6/T7) (Roche, Indianapolis, IN). A nucleotide in $93 \mathrm{bp}$, the same region as used in the northern blot, was cloned into the plasmid pSPT18/19 as a template to generate cRNA. ISH was performed on cryosections $(10 \mu \mathrm{m})$ with the SureSite ${ }^{\circledR}$ II system (Novagen, EMD Biosciences) according to the manufacturer's protocol. The sections were incubated with denatured sense or anti-sense cRNA probes $\left(500 \mathrm{ng} \mathrm{ml}^{-1}\right.$ in hybridization buffer) at $50{ }^{\circ} \mathrm{C}$ for $18 \mathrm{~h}$. The hybridized probes were visualized using anti-digoxigenin Fab fragments (dilution 1:500, Roche, Indianapolis, IN) and BCIP/NBT substrate, and observed under a Nikon Eclipse TE300 microscope.

\subsection{RT-PCR}

Total RNA was prepared from lung and alveolar macrophages with TRIzol ${ }^{\circledR}$ reagent (Invitrogen life technologies) according to the manufacturer's protocol. Two micrograms of RNA was used to prepare the cDNA. The following primers were used in the PCR experiments: LCytb, left: 5'-ATGGCTTCAGGATGGTTT-3', right: 5'-TCATTCCCTGTCATGCAA-3', yield a product of 726 bp, beta-actin, left: 5'-CTGTATTCCCCTCCATCGTG-3' right: 5'TACTCCTGCTTGCTGATCCA-3', yield a product of 1000 bp. LCytb was amplified for 27 cycles and beta-actin was amplified for 23 cycles. The PCR products were separated in 1\% agarose gel and taken picture with Gel Doc 1000 system (Bio-Rad).

\section{Results}

\subsection{LCytb is an ASC-reducible Cyt b561}

A protein-protein BLAST search of the NCBI protein database, using the bovine CGCytb sequence (NCB accession: NP_031831) as a query, revealed the presence of five Cyt b561 homologs in the mouse genome. In addition to the mouse CGCytb, these are Dcytb [6], 101F6 [12,16], and two proteins with yet unknown function, Cyb561d1 (NCB accession: XP_485295) and a hypothetical protein (NCB accession: NP_958739). The latter is characterized in this study. Based on its subcellular localization in the late endosomes and lysosomes (see below), we named the new putative Cyt b561 as LCytb.

Multiple sequence alignment of mouse Cyts b561 revealed that LCytb shared high sequence similarity with CGCytb (45\% identity over 211 amino acids), Dcytb (42\% identity over 217 amino acids), 101F6 (29\% identity over 136 amino acids) and Cyb561d1 (28\% identity over 236 amino acids). LCytb was also highly conserved among different mammals, with $92 \%$ identity to rat putative LCytb (NCB accession: XP_342023), $84 \%$ identity to human putative LCytb (NCB accession: AAH47710), and $83 \%$ identity to the chimpanzee putative LCytb (NCB accession: XP_508473). Secondary structure prediction suggested that LCytb is an intrinsic membrane protein containing six consensus transmembrane domains (Fig. 1). Furthermore, LCytb has four conserved His residues most likely coordinating two heme molecules, and two putative binding sites for ASC and MDA. The $\mathrm{N}$ - and C-terminal ends of the protein were predicted to be localized in the cytoplasm by TMpred [17].

To identify whether LCytb is really a b-type Cyt, mouse LCytb was expressed in yeast. Spectroscopic analysis using microsomal membrane fractions from the transformed yeast cells demonstrated the presence of an ASC-reducible b-type Cyt (Fig. 2). In agreement with earlier observations [13], no ASCreducible Cyts was detected in the microsomal membrane fraction from yeast cells transformed with the empty vector. The $\alpha$-band of the reduced Cyt $b$ is asymmetrical, with a maximum near $561 \mathrm{~nm}$ and a shoulder near $556-557 \mathrm{~nm}$. The level of ASC reduction is about $52 \%$ of the maximal reduction obtained with Na-dithionite. The results therefore demonstrate that LCytb is indeed an ASC-reducible b-type Cyt.

\subsection{Expression of LCytb}

To contribute to our understanding of the physiological function of LCytb, we determined its organs and tissues distribution and its subcellular localization. In Northern blot analyses, the single strand DNA probe of LCytb hybridized with two mRNA bands, one of $3.3 \mathrm{~kb}$, ubiquitously expressed in all organs tested, and another of $3 \mathrm{~kb}$ presented primarily in lung, spleen, thymus, testis, placenta (17.5 d.p.c.), small intestine, and stomach (Fig. 3). Comparing the density of the bands, the highest expression levels of LCytb were observed in lung, spleen, thymus, testis and placenta (17.5 d.p.c.). In 


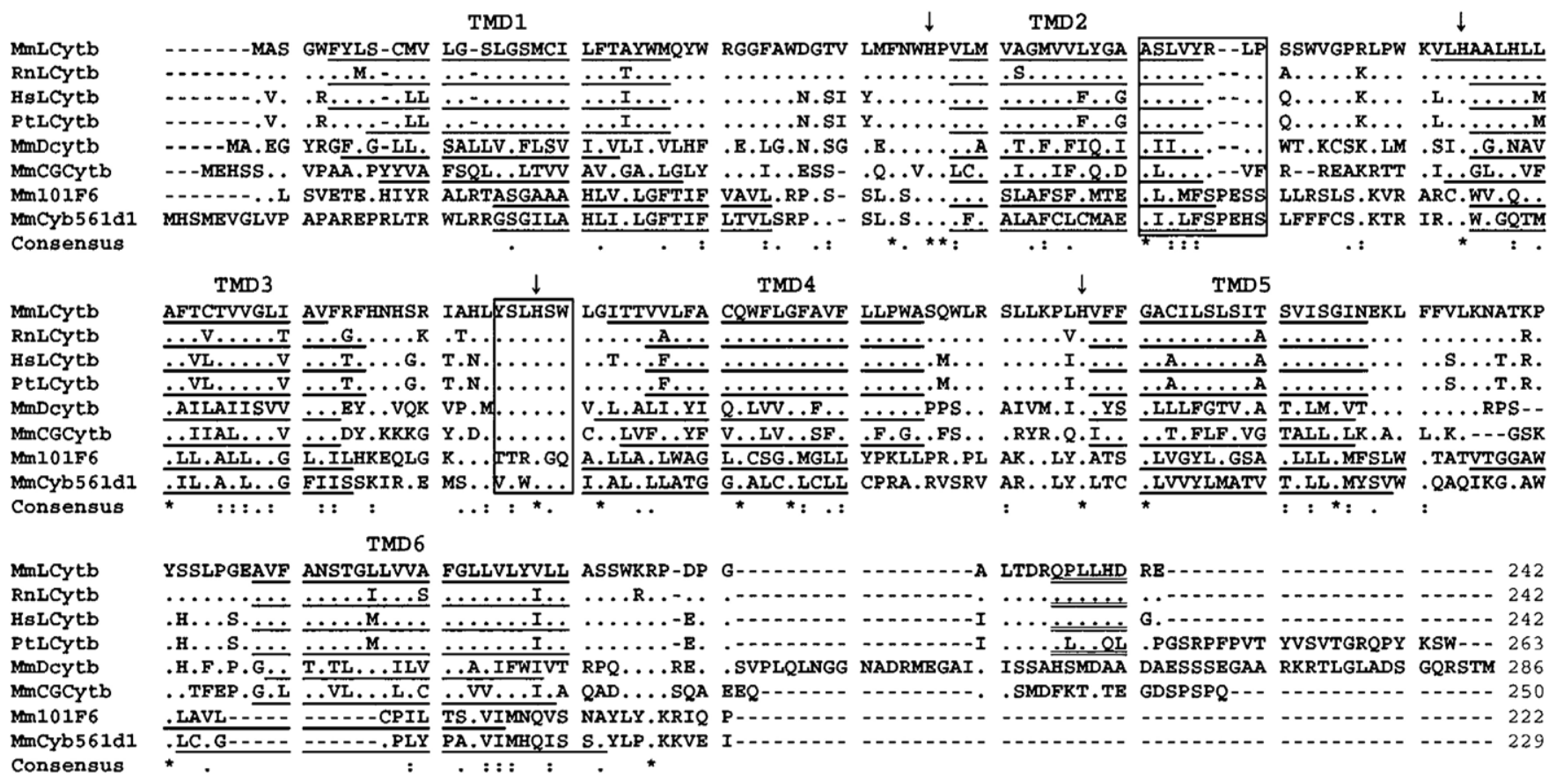

Fig. 1. Multiple sequence alignment of LCytb with other mouse Cyt b561 isoforms. The sequence data for the Cyts were obtained from the NCBI protein database, and their alignment was determined with ClustalX (1.8). The transmembrane domains (TMDs) were predicted with HMMTOP 2.0. As other Cyts b561s, LCytb is predicted to contain six TMDs (TMD1 through TMD6, underlined). Four conserved His (indicated by arrow heads) likely coordinating two heme molecules and putative binding sites for ASC and MDA (boxed) were conserved in the LCytb sequences. The "DRQPLL" signal peptides (double underlining) are putative (DE) XXXL(LI)-type signals, potentially targeting the protein to late endosomes and lysosomes.

comparison, CGCytb was expressed at high levels in brain, lung, kidney, stomach, intestine, testis, unpregnant uterus and placenta (17.5 d.p.c.), and at lower levels in heart, spleen, skeletal muscle and thymus (Fig. 3). The presence of two

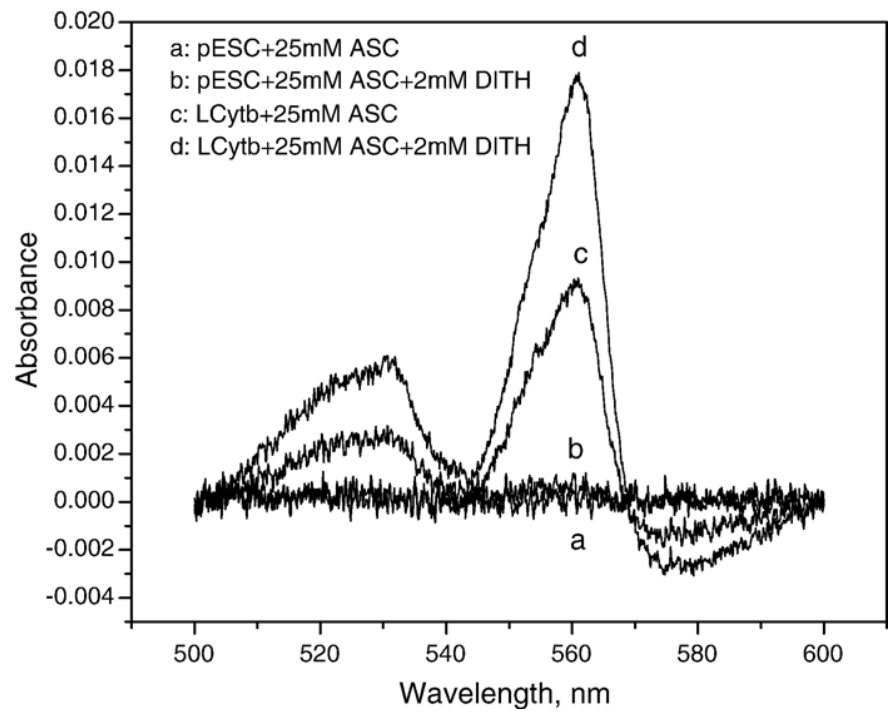

Fig. 2. Reduced-minus-oxidized absorption spectra of recombinant mouse LCytb in yeast microsomal membranes. The absorption spectrum of LCytb exhibited a $\alpha$-band spectrum, with a maximum at $561 \mathrm{~nm}$. The level of ASC reduction at $25 \mathrm{mM}$ ASC was about $52 \%$ of the level reached with dithionite $(2 \mathrm{mM})$. No b-type Cyts were detected in the microsomal membrane fraction of yeast cells transformed with the vector only (pESC). Protein concentration: $2 \mathrm{mg} \mathrm{ml}^{-1}$. transcripts for LCytb can possibly be explained by alternative splicing (see Discussion).

Affinity-purified polyclonal antibodies generated against a C-terminal peptide of LCytb were used to investigate the presence of the LCytb protein in various mouse organs. A band of about $27 \mathrm{kDa}$ was detected on Western blots using microsomal membrane fractions from lung, spleen, thymus and testis. This band corresponds to the predicted mass of LCytb $(27.08 \mathrm{kDa})$, and to the mass of recombinant LCytb expressed in yeast (Fig. 4A). In the yeast recombinant LCytb sample, a band around $40 \mathrm{kDa}$ also was detected. This band

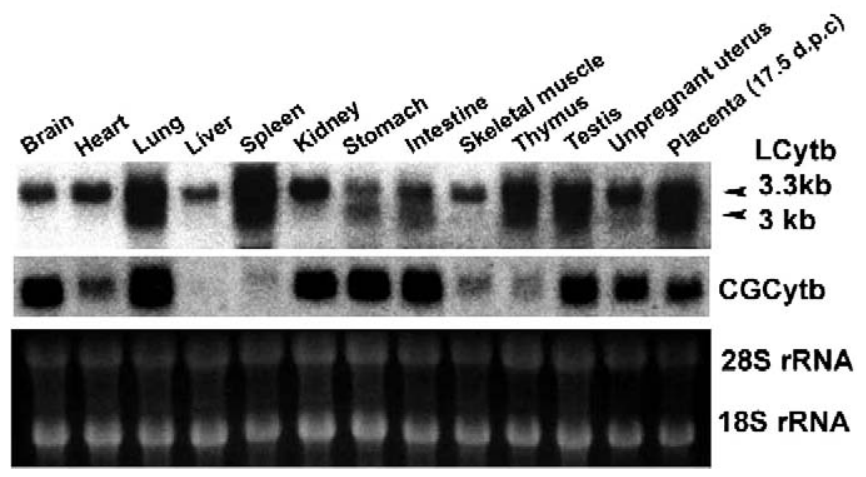

Fig. 3. Northern blot analysis of the expression of LCytb in different mouse organs. A nylon (+) membrane blotted with $20 \mu \mathrm{g}$ total RNA each lane for different mouse organs was hybridized with ${ }^{32} \mathrm{P}$-dCTP labeled LCytb cDNA probe corresponding to the first $93 \mathrm{bp}$ nucleotides of the LCytb encoding region. CGCytb, 18S and 28S rRNA were used as loading control. 
A

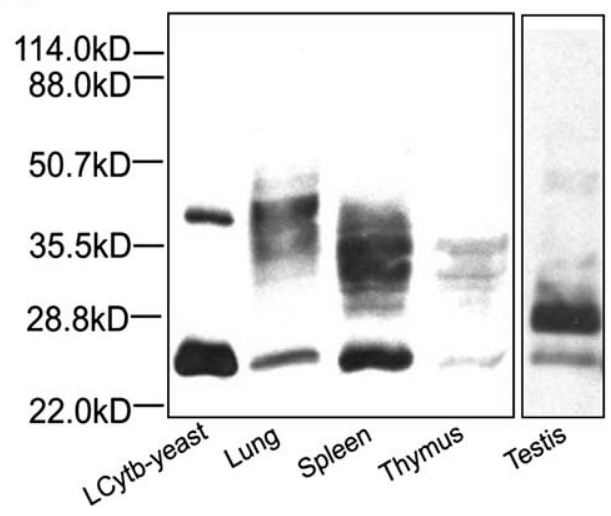

B

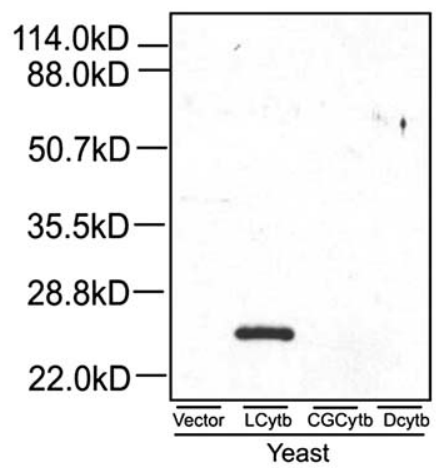

C

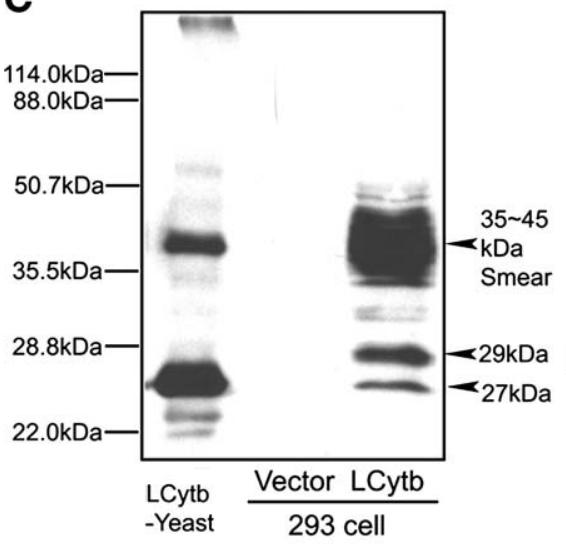

D

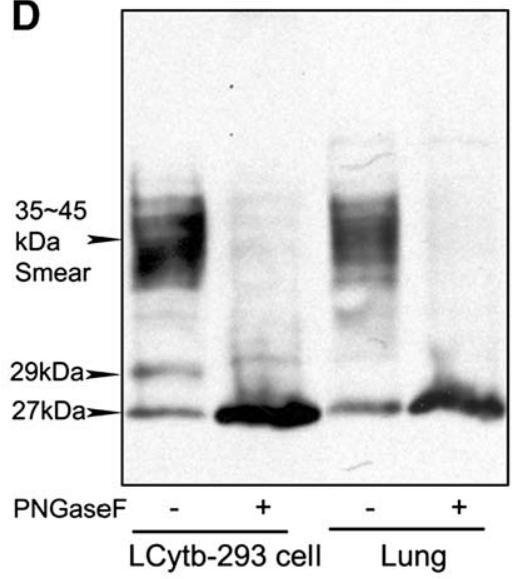

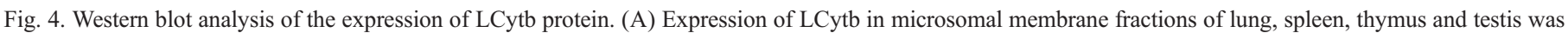

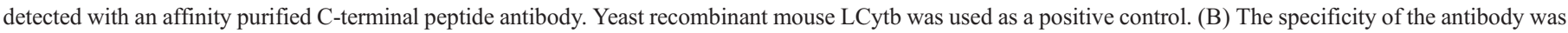

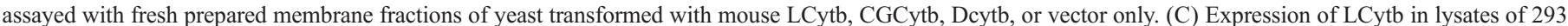

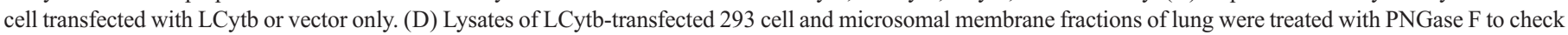
the possibility of glycosylation.

might result from protein aggregation after repeated freezing and thawing of the sample, since there was little if any of this band detected in fresh sample (Fig. 4B). The affinity-purified antibody did not cross-react with any of the other mouse Cyts b561 when expressed in yeast, demonstrating that it was isoform-specific (Fig. 4B). No or little LCytb protein could be detected in microsomal membrane preparations from other mouse organs such as brain, heart, liver and kidney (results not shown). A smear of higher molecular mass bands (35-45 kDa) was also observed in the Western blots from membrane fractions of lung, spleen and thymus (Fig. 4A). In contrast to that, in the testis, a band of about $29 \mathrm{kDa}$ was also detected (Fig. 4A). In the cell lysate of LCytb-transfected 293 cells, a $27 \mathrm{kDa}$ band, a $29 \mathrm{kDa}$ band, and a smeared band at about $35-45 \mathrm{kDa}$ were observed (Fig. 4C). These results demonstrated that these bands in the microsomal membrane fractions of the various mouse organs, specifically resulted from the LCytb expression. Glycosylation of the intrinsic membrane protein DCT1/Nramp2 was reported to cause a smeared band at high molecular mass [18]. Hence, we speculated that glycosylation could also be the cause of the smeared bands observed in the organ membrane fractions. After the LCytb-transfected 293 cell lysate was treated with PNGase F, the band smear and the $29 \mathrm{kDa}$ band almost completely disappeared, while the $27 \mathrm{kDa}$ band was strengthened, which suggested that the $29 \mathrm{kDa}$ band and the band smear result from the glycosylation of the $27 \mathrm{kDa}$ band (Fig. 4D). The effect of glycosylation was also confirmed by the treatment of lung membrane fractions with PNGase F, which resulted in the disappearance of the band smear and enhancement of the $27 \mathrm{kDa}$ band.

\subsection{Tissue localization of LCytb}

To determine the tissue localization of LCytb, we performed ISH and immunofluorescence experiments. The anti-sense cRNA probe specifically labeled particular cell-types in the lung, spleen, thymus and intestine (Fig. 5A). Most of the positive cells in the lung are localized in the alveolus, and a smaller number of positive cells is located in the bronchia (arrow head in Fig. 5Aa). The positive cells in the spleen are mainly localized in the germinal center of the white pulp (Fig. 5Ac). In the thymus, the labeled cells were almost evenly distributed throughout the organ (Fig. 5Ae). In the intestine, a few cells in the lamina propria of the villi were specifically labeled (Fig. 5Ag).

Immunofluorescence studies, using the same C-terminal peptide antibodies used in the Western blots revealed similar 
A

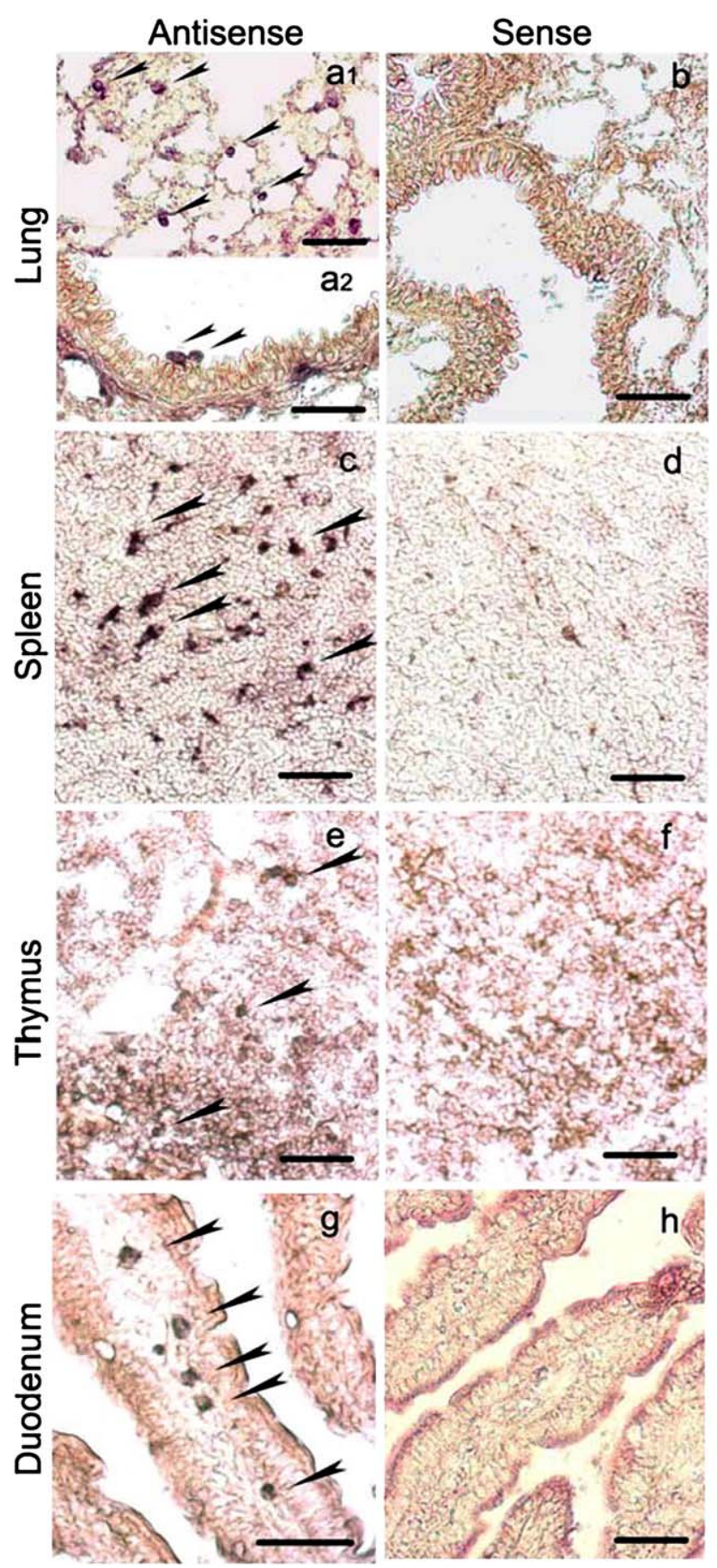

B
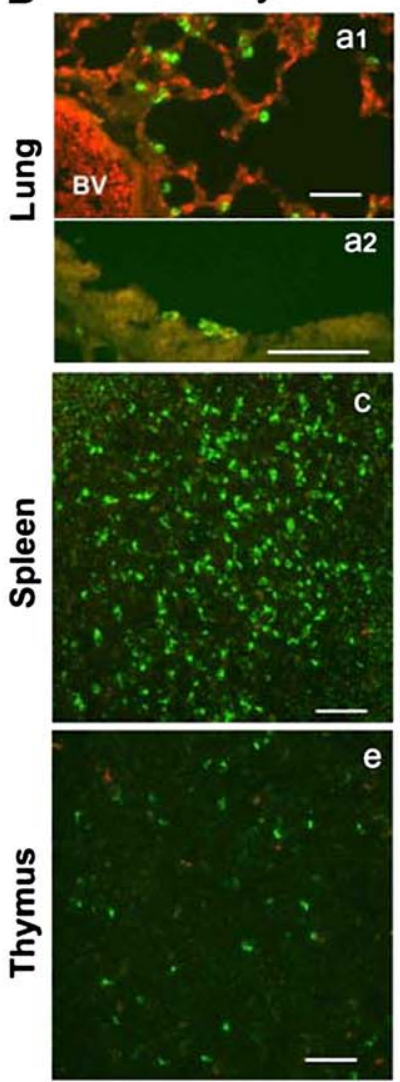

e
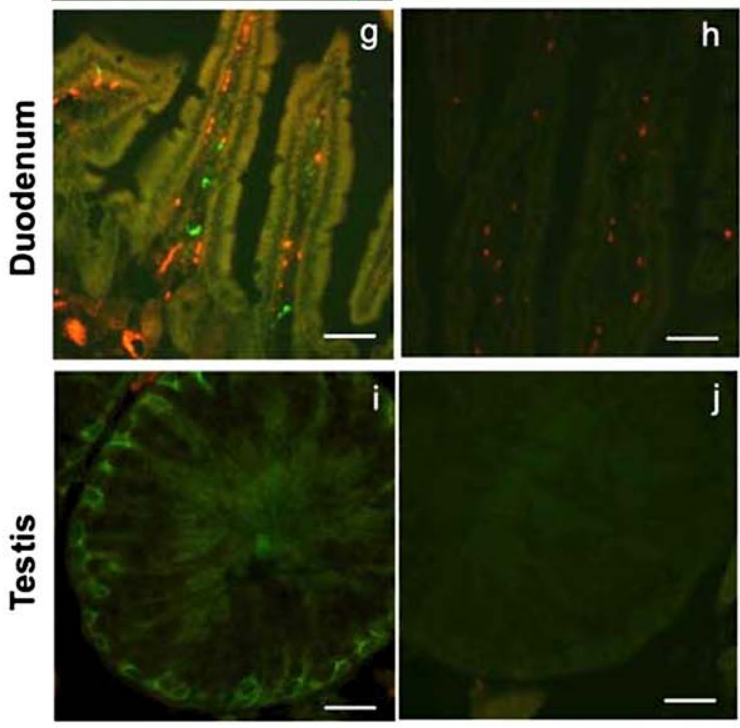

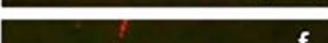

anit-LCytb + peptide

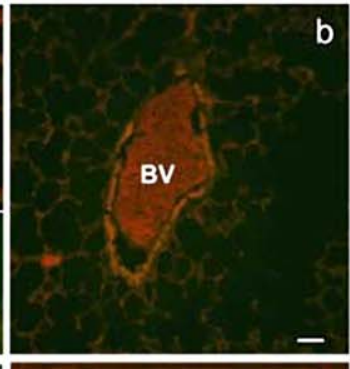

d
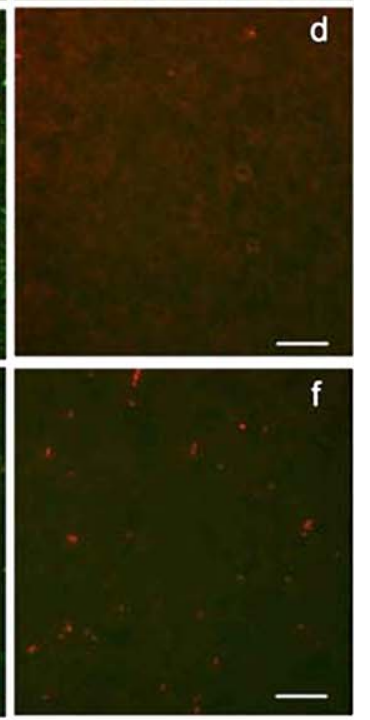

h

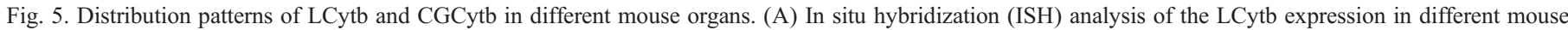

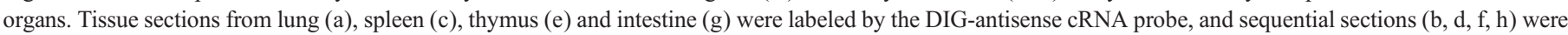

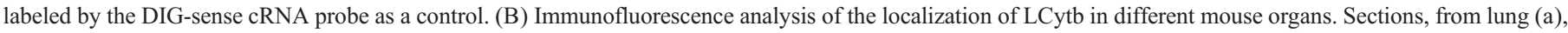

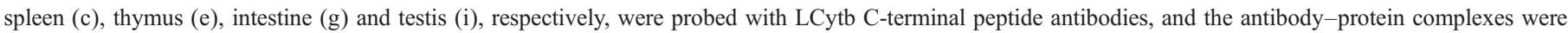

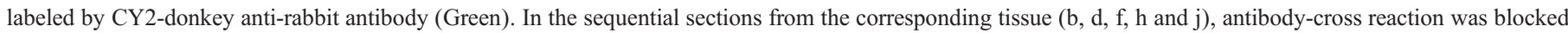

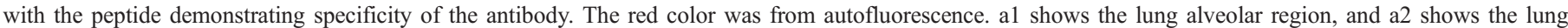

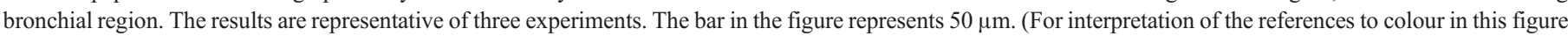
legend, the reader is referred to the web version of this article.)

distributions as observed with the ISH. Cells labeled in the lung were mostly evenly distributed in the alveolar region and appeared to be associated with the wall of the alveolus (green,
Fig. 5Ba1). A few labeled cells were localized in the bronchia (Fig. 5Ba2), while there were no cells labeled in the blood vessel (BV). Comparatively more cells were labeled in the spleen than 
in the lung (Fig. 5Bc). As was also observed with the ISH, these were mainly localized in the germinal center of the white pulp, and a few cells were labeled in the red pulp. The positive cells observed in the thymus were more or less evenly distributed throughout the organ, with slightly more cells labeled in the medulla (Fig. 5Be). A few cells were specifically labeled in the lamina propria of the villi of the intestine (Fig. 5Bg). In the testis, the antibody very specifically labeled Sertoli cells (Fig. 5Bi). However, the fluorescence level in these sections was lower than that in other tissues. To demonstrate the specificity of the antibody, the antibody were preincubated with the C-terminal LCytb peptide before being added to the section, no labeling was found in these sections (Fig. $5 \mathrm{Bb}, \mathrm{d}, \mathrm{f}, \mathrm{h}$ and $\mathrm{j}$ ). A few labeled cells were also found in the cortex, but not in the medulla of the kidney (results not shown). Several other organs were also tested for the presence of the LCytb protein but generally showed no specifically labeled cells (e.g. in brain, heart, liver). In general, the organ localization pattern of the LCytb protein obtained by immunofluorescence corresponds very well to the distribution of the LCytb mRNA obtained by ISH.

\subsection{Identification of the cell type expressing LCytb}

It is clear from the organ localization studies, that LCytb is expressed in specific cell types, such as the Sertoli cells in the testis, and in a well-defined cell type in the lung. As we suspected the positive cells in the lung to be macrophages, we simultaneously labeled lung sections with the LCytb antibody (Fig. 6A, a, d, green) and the macrophage marker Mac-3 (Fig. 6A, b, e, red) [19]. The merge of the images obtained
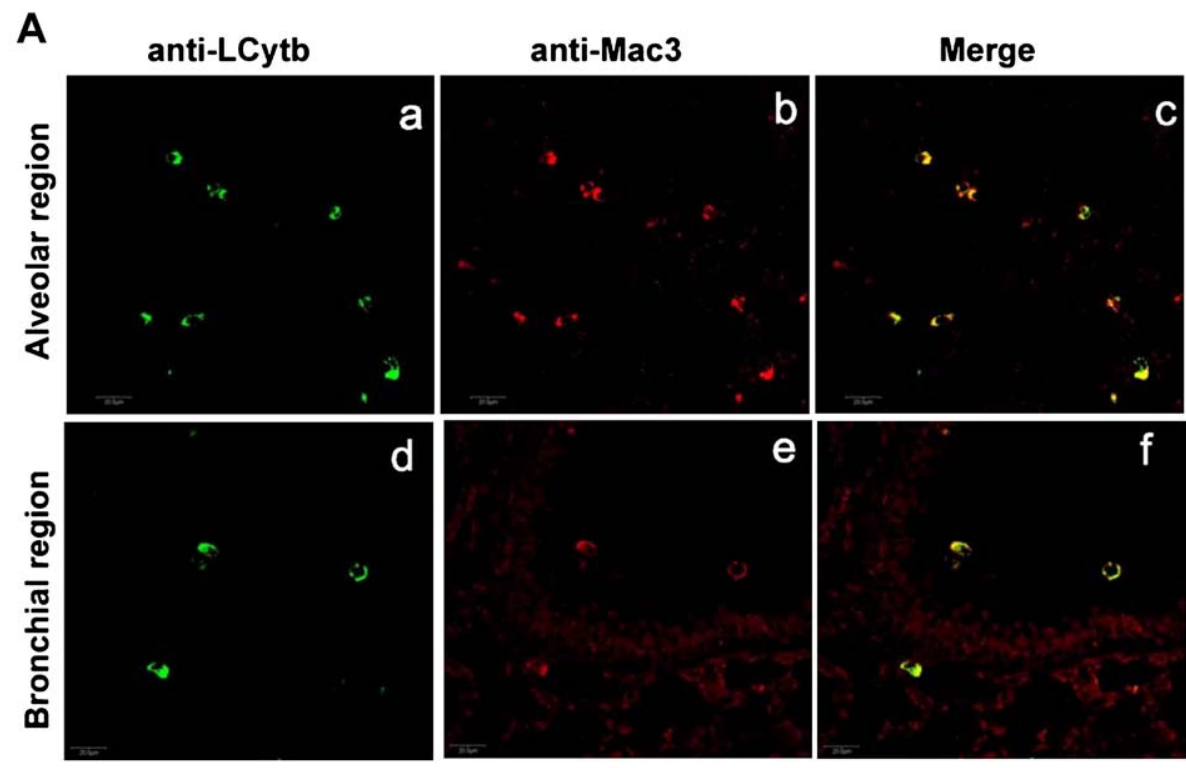

B

C
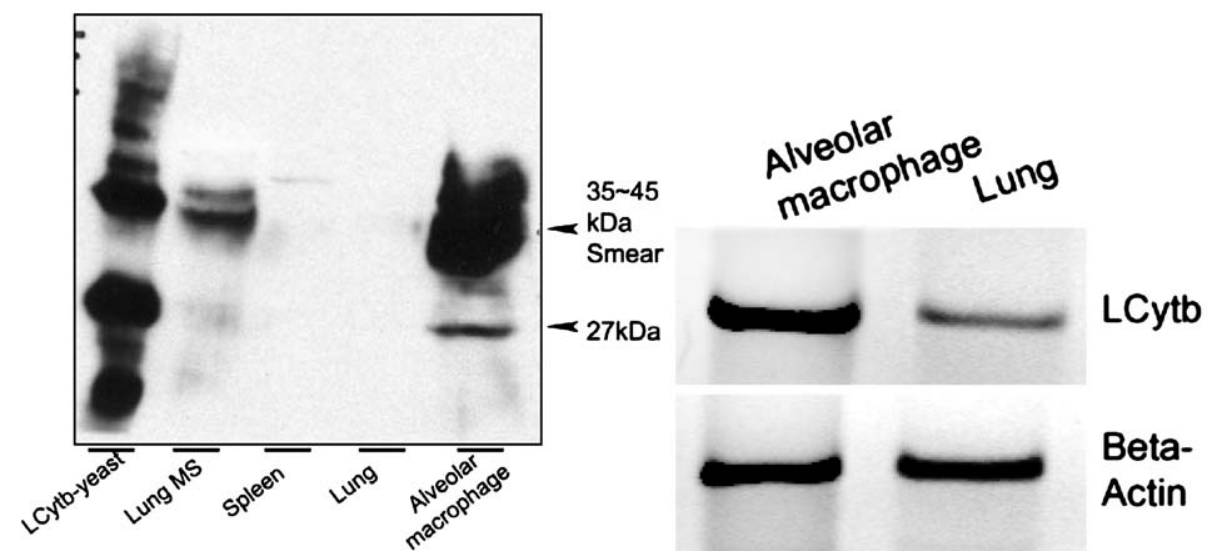

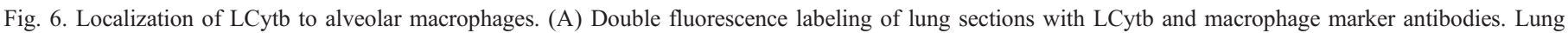

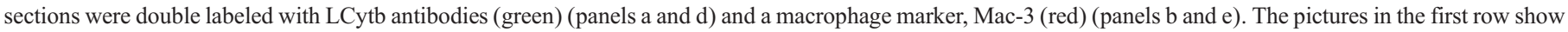

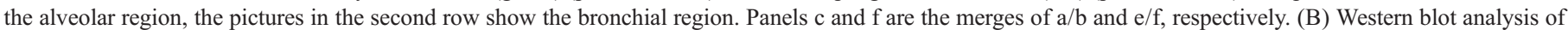

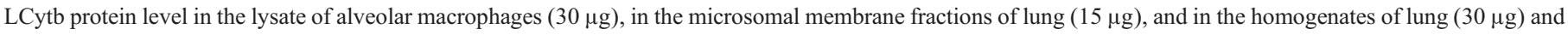

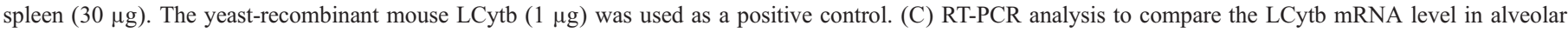
macrophages and lung, beta-actin mRNA level was used as loading control. These results are representative of three experiments. 
with the two antibodies (Fig. 6A, c and f) demonstrated that LCytb was specifically and exclusively expressed in the alveolar macrophages. A marker for type II pneumocytes, SPB (Surfactant-associated protein B) was also applied to these sections, but no overlap between SP-B and LCytb was observed.

In order to confirm the above results, alveolar macrophages were isolated, and the expression of LCytb protein in the lysate

\section{A}

\section{Raw264.7 macrophage-derived cell line transfected with LCytb}
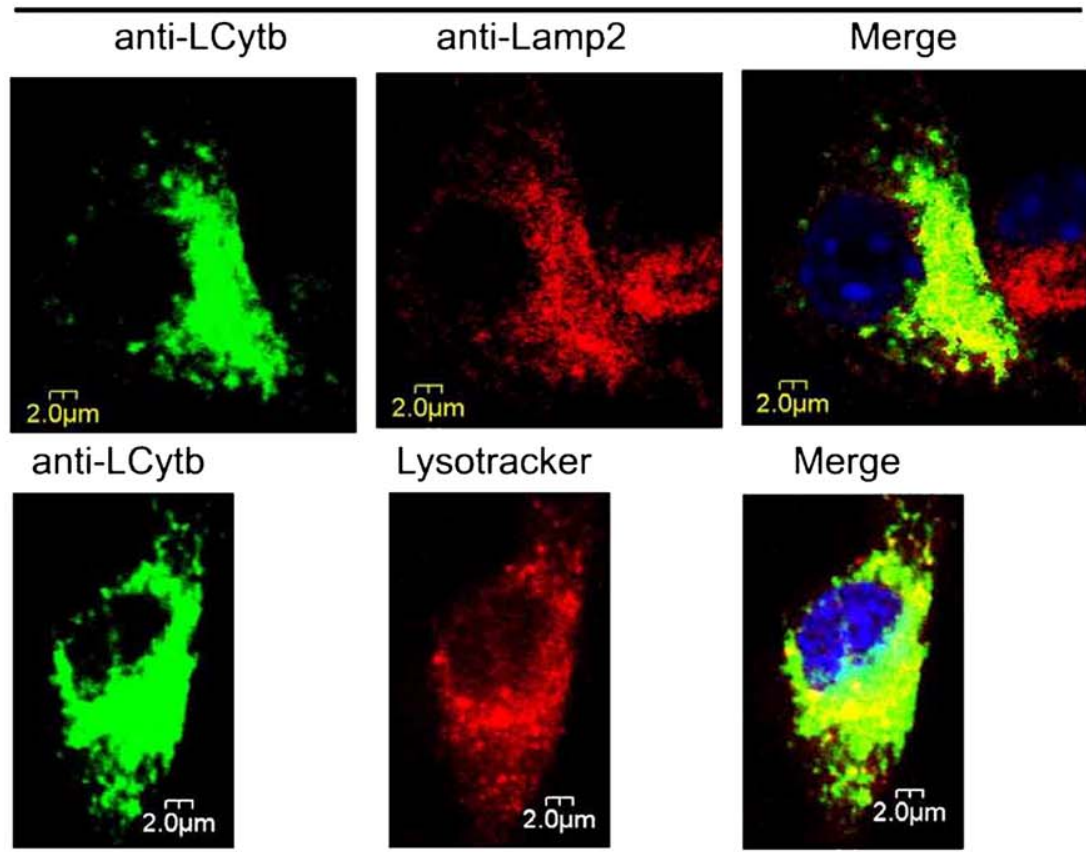

Merge
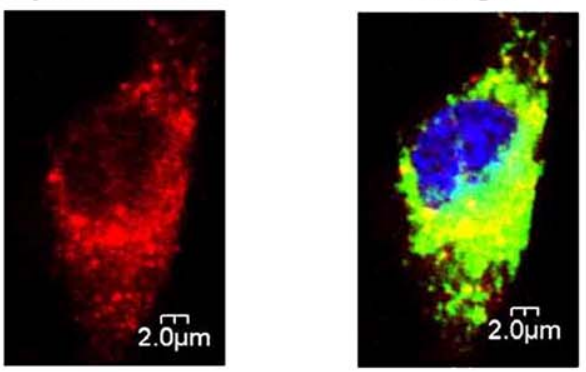

B

293 cell transfected with LCytb
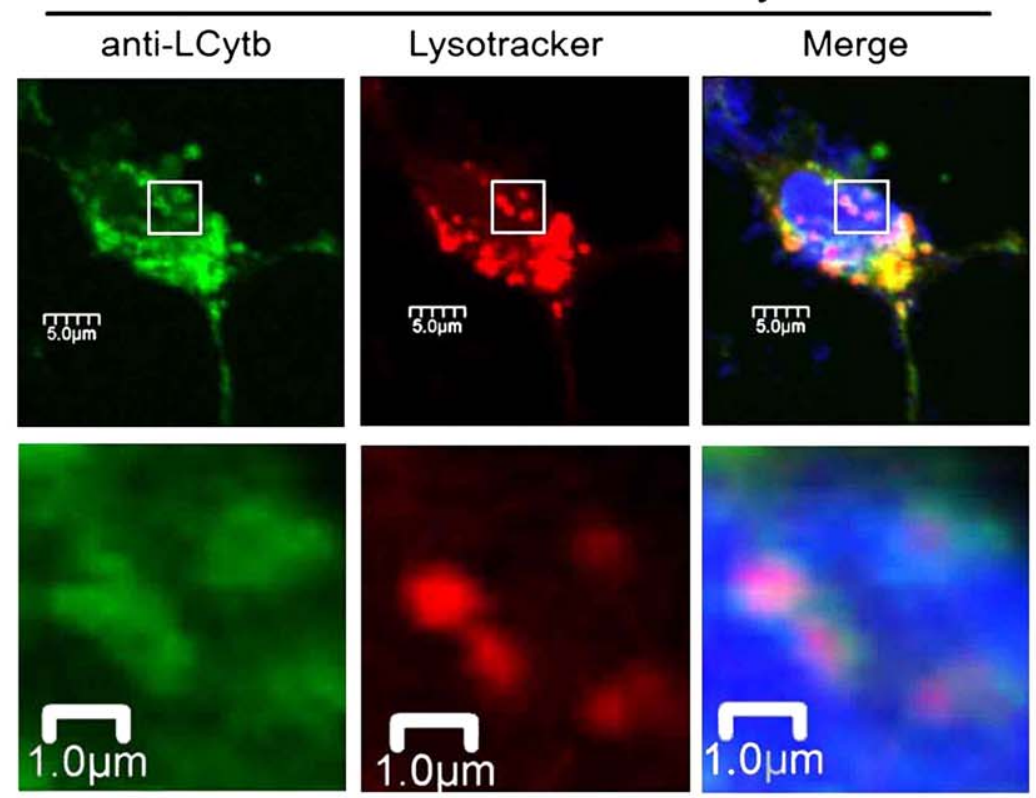

Fig. 7. Subcellular localization of LCytb in RAW264.7 and 293 cells. Double-labeling experiments analyzed the subcellular localization of LCytb in macrophagederived cell lines, RAW264.7 (A) and 293 (B), stably transfected with mouse LCytb. (A) Top row: fluorescence in cells labeled with anti-LCytb antibodies (green), anti-Lamp2 antibodies (red), and the merge of these images. Bottom row: fluorescence in cells labeled with anti-LCytb antibodies, Lysotracker (red), and the merge of these images. (B) Top row: fluorescence in cells labeled with anti-LCytb antibodies, Lysotracker and the merge of these images. Bottom row: higher magnification of the boxed regions in the top row images. The blue signal is the result from nucleotide labeled by DAPI. 
of alveolar macrophages was compared with that in the microsomal membrane fractions of LCytb-transfected yeast and lung, and that in the homogenates of spleen and lung (Fig. $6 \mathrm{~B})$. In the alveolar macrophages lysate, the antibody detected a $27 \mathrm{kDa}$ band and a 35-45 kDa smear of bands, the band and the smeared bands were in the same pattern as that found in the microsomal membrane fractions of lung (Fig. 4). In contrast to alveolar macrophages lysate, the antibody detected very weak, if any, smeared bands at $35-45 \mathrm{kDa}$ in the homogenates of lung and spleen (Fig. 6B). Considering that the intensity of the bands in the alveolar macrophages lysate was comparable to that in microsomal membrane fractions of LCytb-transfected yeast, and was much stronger than that in the microsomal membrane fractions of lung. The results suggested that LCytb is specifically expressed in alveolar macrophages. In accordance with the double labeling (Fig. 6A) and western blot results (Fig. $6 \mathrm{~B})$, the LCytb mRNA level is much higher in alveolar macrophages than that in lung (Fig. 6C).

\subsection{Subcellular Localization of LCytb}

We found that the C-terminal end of the mouse LCytb contained the peptide "DRQPLL" (Fig. 1, double-underlining). This motif was also highly conserved in the LCytb sequences from other mammals, but was absent from the other Cytb 561 isoforms. "DRQPLL" is a putative dileucine-based sorting signal, that belongs to the (DE)XXXL(LI)-type signal family [20]. These signals target membrane proteins to the late endosomes and lysosomes, as well as to specialized endosomal-lysosomal compartments. The "DRQPLL" motif was located at the C-terminal of LCytb, 11 amino acid residues away from the TMD6, consistent with the general location of the (DE)XXXL(LI)-type signals [20]. Moreover, the Pro residue is also partially conserved in these signals [20]. The presence of this motif indicated that LCytb might be localized in the membrane of the late endosomes and lysosomes.

Since the expression level of the endogenous LCytb was low in cell lines, the subcellular localization of LCytb was studied in the RAW264.7 and 293 cells stably transfected with the mouse LCytb gene, using double-labeling fluorescence (Fig. 7). Two markers were used to determine the subcellular localization of LCytb, respectively, an antibody against Lamp2 (Lysosomalassociated membrane protein 2), and the so-called Lysotracker, a weakly basic amine selectively accumulating in cellular compartments with low internal $\mathrm{pH}$. In the LCytb transfected RAW264.7 cell (Fig. 7A, upper panel), the fluorescence from the LCytb antibody (green) overlapped closely with that from Lamp2 (red). Similar results were obtained when the RAW264.7 cells were co-labeled with the LCytb antibodies and lysotracker (red) (Fig. 7A, lower panel). To verify these results, the localization of LCytb was studied in the stably transfected 293 cell line (Fig. 7B). Fluorescence of the LCytb antibody and lysotracker appeared located in discrete particles, and the two distributions patters overlapped very well (Fig. 7B, upper panel). In a higher magnification of the merged images, it was observed that the lysotracker accumulated into small particles, which appeared surrounded by the fluorescence from the LCytb antibodies (Fig. 7B, lower panel). These results strongly suggested that LCytb is localized in the late endosomal-lysosomal membrane, and confirmed the localization predicted by the signal peptide.

\section{Discussion}

Cytochromes b561 are a family of intrinsic membrane proteins, involved in ASC-driven transmembrane electron transport. Although CGCytb, the first member identified in this family, has been studied for almost 30 years, there is little known about the other members of this protein family. In this work, a new Cyt b561 isoform, LCytb, was studied with Northern blot, Western blot, ISH and immunofluorescence.

LCytb has high sequence similarity with the other Cyt b561 isoforms (identity from $28 \%$ to $45 \%$ ), it is also conserved in different mammals (identity from $83 \%$ to $92 \%$ ). Moreover, LCytb has all of the structural elements found in Cyts b561. As other Cyts b561, LCytb has six predicted transmembrane domains, probably with the $\mathrm{N}$ - and C-termini in the cytoplasma (Fig. 1) [17]. Two fully conserved pairs of His residues (H47H117 and H83-H156) are predicted to coordinate two heme molecules on opposite sides of the membrane respectively, conferring the property of transmembrane electron transport on the protein. The putative ASC and MDA binding motifs are conserved in LCytb, suggesting that LCytb could possibly utilize ASC and MDA as electron donor and acceptor [4]. Expression of the mouse LCytb gene in yeast demonstrated that this protein was indeed an ASC-reducible b-type Cyt, with a $\alpha$ band spectra almost identical to that of yeast recombinantCGCytb and bovine CGCytb [13] (Fig. 2).

To start to understand the physiological role of this new Cyt b561, we performed tissue and cellular localization studies. Northern blot analyses, using a LCytb-specific probe corresponding to the $5^{\prime}$-terminus of the encoding region, demonstrated a $3.3 \mathrm{~kb}$ band ubiquitously present in all of the organs tested and a $3 \mathrm{~kb}$ band primarily present in lung, spleen, thymus, testis and placenta (Fig. 3). The two bands are possibly derived from alternative splicing. It is noteworthy that we were only able to detect the LCytb protein by immunofluorescence in the organs that showed the $3 \mathrm{~kb}$ band, which suggests that alternative splicing might result in the loss of the C-terminal epitope used to generate the antibody. The organ distribution pattern of LCytb is very different from those of two other Cyts b561, CGCytb and Dcytb. CGCytb was mainly found in the adrenal medulla, the pituitary gland and other neuroendocrine tissues [21-23], while Dcytb was mainly found in the duodenum and was possibly present in spleen, liver, brain, leucocytes, erythrocytes and neutrophils [6,24,25].

The purified polyclonal antibody generated against a $\mathrm{C}$ terminal peptide detected three bands, including a $27 \mathrm{kDa}$ band (present in the samples of lung, spleen, thymus and testis), a stronger smeared band (present in the samples of lung, spleen and thymus), and a $29 \mathrm{kDa}$ band (present only in testis) (Fig. 4). Deglycosylation treatment with PNGase F indicated that the smeared bands and the $29 \mathrm{kDa}$ band resulted from glycosylation of the $27 \mathrm{kDa}$ protein. Therefore, the $27 \mathrm{kDa}$ band could represent the premature form of LCytb, in the process of 
maturation it is subject to different glycosylation, and the glycosylation for the protein in testis is different from that in other tissues. Because of differences in glycosylation, the protein might be endowed with different function or different compartmentalization, and this warrants further investigation.

To investigate the distribution of LCytb in tissues and organs, ISH and immunohistochemistry experiments were applied and yielded consistent results. In lung, LCytb was found expressed in the bronchial and alveolar region, double labeling with Mac-3 suggested that LCytb is expressed in a specific cell type in this organ, alveolar macrophages. In testis LCytb was specifically localized in Sertoli cells. The expression of LCytb in macrophages and Sertoli cells was confirmed in thioglycollate-elicited peritoneal macrophages, in the macrophage-derived cell lines, J774a.1 and RAW264.7, and in the Sertoli cell line MSC-1, using of RT-PCR and immunocytochemistry techniques (unpublished data). LCytb was also found expressed in the white pulp of spleen, in the lamina propria of the intestinal villi, and in thymus, however, the cell type expressing LCytb in these tissues is not known yet. It is remarkable that in an organ that expresses two distinct Cyt b561 isoforms, such as the intestine, expressing Dcytb and LCytb, these proteins are found in different regions. Dcytb is restricted to the brush border membrane [6], whereas LCytb is found in the lamina propria of the villi (Fig. $5 \mathrm{~g}$ ).

The C-terminal portion of LCytb contains a (DE)XXXL(LI)type signal peptide, putatively targeting the protein to late endosomal-lysosomal membranes. This speculation is supported by double-labeling experiments, using stably transfected macrophage cell line, RAW264.7 and 293 cell line (Fig. 7). The localization of LCytb to the lysosomal membrane is remarkably consistent with the localization of other Cyts b561 that have been studied so far, to membranes separating an acidic and neutral compartment. CGCytb is localized in chromaffin vesicles with an acidic interior $\mathrm{pH}[26,27]$, Dcytb is localized in the plasma membrane of cells lining the acidic intestinal lumen [6], and a plant Cyt b561 (AtCytb1) has recently been localized to the vacuolar membrane, separating the acidic vacuolar content from the cytoplasm [28]. It has been argued that the existence of $\mathrm{pH}$ and charge gradients over the chromaffin vesicle membrane facilitates the electron transfer mediated by CGCytb from cytoplasmic ASC to MDA in the vesicle lumen [29]. It seems likely that similar $\mathrm{pH}$ gradients support the activity of the other members of this protein family.

As other Cyts b561, the electron donor for LCytb probably is cytoplasmic ASC, which is supported by the conserved ASC binding site in the loop toward the cytoplasm (Fig. 1) and by the reduction of yeast recombinant LCytb by ASC (Fig. 2). The electron acceptor for LCytb is not known yet, considering the sequence similarity, LCytb might have similar electron acceptor as its homologs. It could be MDA as that of CGCytb, in this case LCytb should have the ability to recycle ASC inside the late endosomes and lysosomes. Another possible electron acceptor could be the ferric ion as is likely for Dcytb. Ferric reductase activity for LCytb has indeed recently been demonstrated by expressing the protein in yeast cells [30]. It is notable that also CGCytb was recently reported to have ferric reductase activity, and ferric reductase activity also was predicted for other isoforms of Cyts b561 [3,31].

Iron is an essential nutrient for almost all organisms, involved in a series of metabolic processes including electron transport, DNA synthesis, ATP production and cell division. Because of the low solubility of ferric ion, ferrous ion is the biologically available form, and ferric ion has to be reduced into ferrous ion for transporting by DCT1/Nramp2 that is localized in membranes of different cell types, such as apical membrane of duodenal enterocytes and endosomal membrane of macrophages [32,33]. For duodenal enterocytes, it probably is Dcytb that reduces the ferric ion into ferrous to facilitate the transport by DCT1/Nramp2 [6]. Dcytb displays ferric reductase activity when it is expressed in Xenopus oocytes and yeast cells, and its expression is up-regulated by iron-deficient diet and downregulated by iron-replete diet in mice, similar as DCT1/Nramp2 $[6,24]$. For macrophages, an unknown ferric reductase localized in the endosomal membrane was suggested $[7,8,34]$. Therefore, LCytb could very well be a candidate for this ferric reductase facilitating Nramp2/DCT1-mediated transfer of iron into the cytoplasm.

In conclusion, LCytb, a new isoform of ASC-reducible Cyts b561, is described here. It is mainly expressed in the lung, spleen, thymus, intestine and testis. LCytb expressed specifically in the alveolar macrophages of lung, and also expressed in the Sertoli cells of testis. Signal peptide analysis and fluorescence studies suggested that LCytb is localized in the membranes of late endosomes and lysosomes.

\section{Acknowledgements}

We thank Dr. You (Joe) Zhou and Dr. Andrea Cupp for the valuable discussions and technical assistance, Drs. Jeffrey Cirillo, Luan Cirillo and Andrea Cupp for cell cultures. This work was supported by an NIH-CoBRE grant (1P20RR17675).

\section{References}

[1] G.J. Harnadek, E.A. Ries, D.G. Tse, J.S. Fitz, D. Njus, Electron transfer in chromaffin-vesicle ghosts containing peroxidase, Biochim. Biophys. Acta 1135 (1992) 280-286.

[2] W. Verelst, H. Asard, A phylogenetic study of cytochrome b561 proteins, Genome Biol. 4 (2003) R38.

[3] C.P. Ponting, Domain homologues of dopamine beta-hydroxylase and ferric reductase: roles for iron metabolism in neurodegenerative disorders? Hum. Mol. Genet. 10 (2001) 1853-1858.

[4] M. Tsubaki, M. Nakayama, E. Okuyama, Y. Ichikawa, H. Hori, Existence of two heme B centers in cytochrome b561 from bovine adrenal chromaffin vesicles as revealed by a new purification procedure and EPR spectroscopy, J. Biol. Chem. 272 (1997) 23206-23210.

[5] M.S. Perin, V.A. Fried, C.A. Slaughter, T.C. Sudhof, The structure of cytochrome b561, a secretory vesicle-specific electron transport protein, EMBO J. 7 (1988) 2697-2703.

[6] A.T. McKie, D. Barrow, G.O. Latunde-Dada, A. Rolfs, G. Sager, E. Mudaly, M. Mudaly, C. Richardson, D. Barlow, A. Bomford, T.J. Peters, K.B. Raja, S. Shirali, M.A. Hediger, F. Farzaneh, R.J. Simpson, An ironregulated ferric reductase associated with the absorption of dietary iron, Science 291 (2001) 1755-1759.

[7] K. Pantopoulos, Iron metabolism and the IRE/IRP regulatory system: an update, Ann. N. Y. Acad. Sci. 1012 (2004) 1-13. 
[8] M.W. Hentze, M.U. Muckenthaler, N.C. Andrews, Balancing acts: molecular control of mammalian iron metabolism, Cell 117 (2004) 285-297.

[9] D.M. Frazer, S.J. Wilkins, C.D. Vulpe, G.J. Anderson, The role of duodenal cytochrome $\mathrm{b}$ in intestinal iron absorption remains unclear, Blood 106 (2005) 4413 (author reply 4414).

[10] H. Gunshin, C.N. Starr, C. Direnzo, M.D. Fleming, J. Jin, E.L. Greer, V.M. Sellers, S.M. Galica, N.C. Andrews, Cybrd1 (duodenal cytochrome b) is not necessary for dietary iron absorption in mice, Blood (2005).

[11] Y. Sekido, M. Ahmadian, Wistuba II, F. Latif, S. Bader, M.H. Wei, F.M. Duh, A.F. Gazdar, M.I. Lerman, J.D. Minna, Cloning of a breast cancer homozygous deletion junction narrows the region of search for a $3 \mathrm{p} 21.3$ tumor suppressor gene, Oncogene 16 (1998) 3151-3157.

[12] L. Ji, M. Nishizaki, B. Gao, D. Burbee, M. Kondo, C. Kamibayashi, K. Xu, N. Yen, E.N. Atkinson, B. Fang, M.I. Lerman, J.A. Roth, J.D. Minna, Expression of several genes in the human chromosome 3p21.3 homozygous deletion region by an adenovirus vector results in tumor suppressor activities in vitro and in vivo, Cancer Res. 62 (2002) 2715-2720.

[13] A. Berczi, D. Su, M. Lakshminarasimhan, A. Vargas, H. Asard, Heterologous expression and site-directed mutagenesis of an ascorbate-reducible cytochrome b561, Arch. Biochem. Biophys. 443 (2005) 82-92.

[14] M.A. Markwell, S.M. Haas, L.L. Bieber, N.E. Tolbert, A modification of the Lowry procedure to simplify protein determination in membrane and lipoprotein samples, Anal. Biochem. 87 (1978) 206-210.

[15] P.G. Holt, Alveolar macrophages. I. A simple technique for the preparation of high numbers of viable alveolar macrophages from small laboratory animals, J. Immunol. Methods 27 (1979) 189-198.

[16] M.I. Lerman, J.D. Minna, The 630-kb lung cancer homozygous deletion region on human chromosome 3 p21.3: identification and evaluation of the resident candidate tumor suppressor genes. The International Lung Cancer Chromosome 3p21.3 Tumor Suppressor Gene Consortium, Cancer Res. 60 (2000) 6116-6133.

[17] K. Hoffman, W. Stoffel, TMbase-A database of membrane spanning proteins segments, Biol. Chem. Hoppe-Seyler 374 (1993) 166.

[18] M. Tabuchi, T. Yoshimori, K. Yamaguchi, T. Yoshida, F. Kishi, Human NRAMP2/DMT1, which mediates iron transport across endosomal membranes, is localized to late endosomes and lysosomes in HEp-2 cells, J. Biol. Chem. 275 (2000) 22220-22228.

[19] M.K. Ho, T.A. Springer, Tissue distribution, structural characterization, and biosynthesis of Mac-3, a macrophage surface glycoprotein exhibiting molecular weight heterogeneity, J. Biol. Chem. 258 (1983) 636-642.

[20] J.S. Bonifacino, L.M. Traub, Signals for sorting of transmembrane proteins to endosomes and lysosomes, Annu. Rev. Biochem. 72 (2003) 395-447.
[21] L.T. Duong, P.J. Fleming, J.T. Russell, An identical cytochrome b561 is present in bovine adrenal chromaffin vesicles and posterior pituitary neurosecretory vesicles, J. Biol. Chem. 259 (1984) 4885-4889.

[22] T. Flatmark, O. Terland, Cytochrome b 561 of the bovine adrenal chromaffin granules. A high potential b-type cytochrome, Biochim. Biophys. Acta 253 (1971) 487-491.

[23] R.M. Pruss, E.A. Shepard, Cytochrome b561 can be detected in many neuroendocrine tissues using a specific monoclonal antibody, Neuroscience 22 (1987) 149-157.

[24] G.O. Latunde-Dada, J. Van der Westhuizen, C.D. Vulpe, G.J. Anderson, R.J. Simpson, A.T. McKie, Molecular and functional roles of duodenal cytochrome B (Dcytb) in iron metabolism, Blood Cells, Mol. Dis. 29 (2002) 356-360.

[25] V. Escriou, F. Laporte, J. Garin, G. Brandolin, P.V. Vignais, Purification and physical properties of a novel type of cytochrome $b$ from rabbit peritoneal neutrophils, J. Biol. Chem. 269 (1994) 14007-14014.

[26] D.K. Apps, J.G. Pryde, J.H. Phillips, Cytochrome b561 is identical with chromomembrin B, a major polypeptide of chromaffin granule membranes, Neuroscience 5 (1980) 2279-2287.

[27] R.G. Johnson, A. Scarpa, Internal pH of isolated chromaffin vesicles, J. Biol. Chem. 251 (1976) 2189-2191.

[28] D. Griesen, D. Su, A. Berczi, H. Asard, Localization of an ascorbatereducible cytochrome b561 in the plant tonoplast, Plant Physiol. 134 (2004) 726-734.

[29] D. Njus, P.M. Kelley, The secretory-vesicle ascorbate-regenerating system: a chain of concerted $\mathrm{H}+/ \mathrm{e}(-)$-transfer reactions, Biochim. Biophys. Acta 1144 (1993) 235-248.

[30] D. Su, H. Asard, Three mammalian cytochromes b561 are ascorbatedependent ferrireductases, FEBS Journal (2006) 3722-3734.

[31] J.D. Vargas, B. Herpers, A.T. McKie, S. Gledhill, J. McDonnell, M. van den Heuvel, K.E. Davies, C.P. Ponting, Stromal cell-derived receptor 2 and cytochrome b561 are functional ferric reductases, Biochim. Biophys. Acta 1651 (2003) 116-123.

[32] S. Gruenheid, F. Canonne-Hergaux, S. Gauthier, D.J. Hackam, S. Grinstein, P. Gros, The iron transport protein NRAMP2 is an integral membrane glycoprotein that colocalizes with transferrin in recycling endosomes, J. Exp. Med. 189 (1999) 831-841.

[33] S. Tandy, M. Williams, A. Leggett, M. Lopez-Jimenez, M. Dedes, B. Ramesh, S.K. Srai, P. Sharp, Nramp2 expression is associated with pHdependent iron uptake across the apical membrane of human intestinal Caco-2 cells, J. Biol. Chem. 275 (2000) 1023-1029.

[34] N.C. Andrews, Metal transporters and disease, Curr. Opin. Chem. Biol. 6 (2002) 181-186. 